\title{
Chilaiditi's syndrome with interposed sigmoid colon mimicking traumatic pneumoperitoneum
}

\author{
Wen-Cheng Liu MD¹, Chih-Weim Hsiang MD², Chang-Hsien Liu MD², Guo-Shu Huang MD²
}

\section{CASE PRESENTATION}

A 61-year-old man experienced a contusion on the right hypochondrium in a traffic accident. He was immediately taken to the emergency department and presented with severe pain over the contusion site. His surgical history was unremarkable. On arrival, physical examination revealed decreased breathing sounds in the right lower lung area on auscultation. Distention, hypertympanic percussion and local tenderness over the right upper quadrant of abdomen were also observed. A posteroanterior chest radiograph revealed elevation of the right hemidiaphragm with concerning features for subphrenic free air as well as fracture of right fifth to eighth ribs (Figure 1A). A computed tomography scan of the abdomen with coronal reconstruction revealed hepatodiaphragmatic interposition of the dilated sigmoid colon (Figure 1B). No evidence of pneumoperitoneum was identified. Conservative treatment with oxygenation, chest care and pain control was performed. After the medical therapy, the patient was discharged uneventfully.

\section{DISCUSSION}

Chilaiditi's sign, first described by Demetrius Chilaiditi in 1910, is a rare and asymptomatic manifestation of the hepatodiaphragmatic interposition of the bowel, involving especially the transverse colon (1). Only seven patients with interposed sigmoid colon have been reported $(2,3)$. Previous literature had suggested that Chilaiditi's sign was attributed to anatomical variations, including absence of the suspensory ligaments of the transverse colon and falciform ligament of the liver, redundant colon, right diaphragmatic paralysis and enlargement of the thorax leaving extra space for potential colon migration (4). The differential diagnosis of the right subphrenic airspace included Chilaiditi's sign, pneumoperitoneum, diaphragmatic hernia and subdiaphragmatic abscess. A computed tomography scan with coronal reconstruction yielded a definite diagnosis before treatment. Unlike pneumoperitoneum, invasive management of Chilaiditi's sign was unnecessary (5). Surgical intervention was only indicated if a symptomatic complication, such as colonic volvulus or bowel obstruction associated Chilaiditi's sign, developed.

\section{REFERENCES}

1. Chilaiditi D. Zur frage der hepatoptose und ptose im allgemeinen im anschlussan drei falle von temporarer, partieller leberverlagerung. Fortschr Geb Rontgenstr Nuklearmed Erganzungsband 1910;16:173-208.

2. Kurt Y, Demirbas S, Bilgin G, et al. Colonic volvulus associated with Chilaiditi's syndrome: Report of a case. Surg Today 2004;34:613-5.

3. Sugimoto S, Mizukami T, Morohoshi Y, Komatsu H. Sigmoid volvulus associated with Chilaiditi's syndrome. Intern Med 2013;52:515-6.

4. Kamiyoshihara M, Ibe T, Takeyoshi I. Chilaiditi's sign mimicking a traumatic diaphragmatic hernia. Ann Thorac Surg 2009;87:959-61.

5. Saber AA, Boros MJ. Chilaiditi's syndrome: What should every surgeon know? Am Surg 2005;71:261-3.

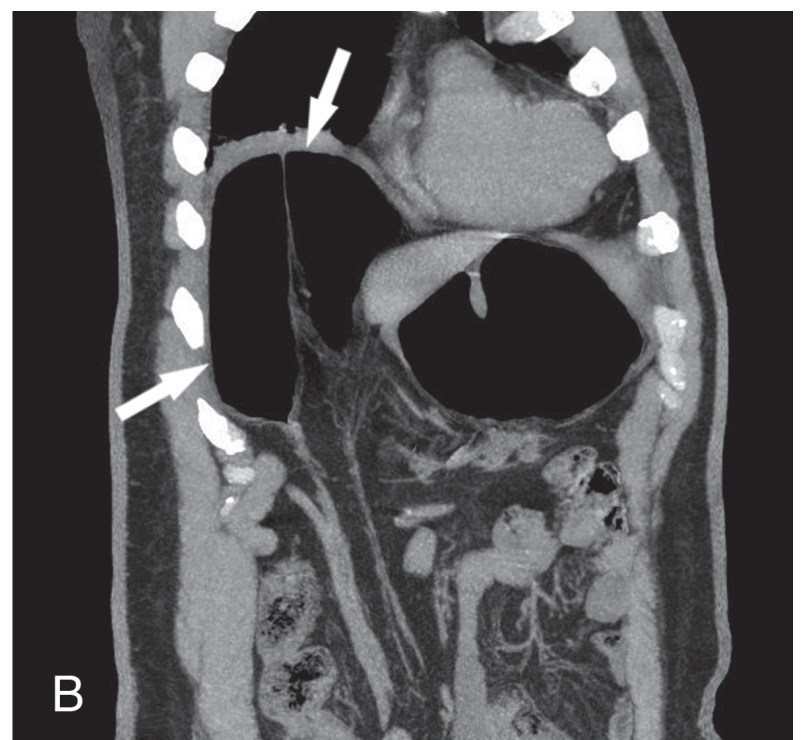

Figure 1) A Posteroanterior chest radiograph showing elevation of the right hemidiaphragm with fracture of right ribs five to eight and suspected subphrenic free air. B Abdominal computed tomography scan with coronal reconstruction showing heptodiaphragmatic interposition of the sigmoid colon (white arrows) without pneumoperitonium

The Canadian Journal of Gastroenterology is now considering a limited number of submissions for IMAGE OF THE MONTH. These are based on endoscopic, histological, radiological and/or patient images, which must be anonymous with no identifying features visible. The patient must consent to publication and the consent must be submitted with the manuscript. All manuscripts should be practical and relevant to clinical practice, and not simply a case report of an esoteric condition. The text should be brief, structured as CASE PRESENTATION and DISCUSSION, and not more than 700 words in length. A maximum of three images can be submitted and the number of references should not exceed five. The submission may be edited by our editorial team.

${ }^{1}$ Department of Internal Medicine; ${ }^{2}$ Department of Radiology, Tri-Service General Hospital, National Defense Medical Center, Taipei, Taiwan

Correspondence: Dr Chang-Hsien Liu, No. 325, Section 2, Cheng-Kung Road, Neihu 114, Taipei, Taiwan. Telephone 886-2-87927244,

fax886-2-87927245, e-mail cute610627@yahoo.com.tw

Received for publication May 3, 2013. Accepted May 6, 2013 


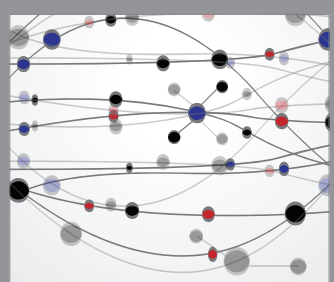

The Scientific World Journal
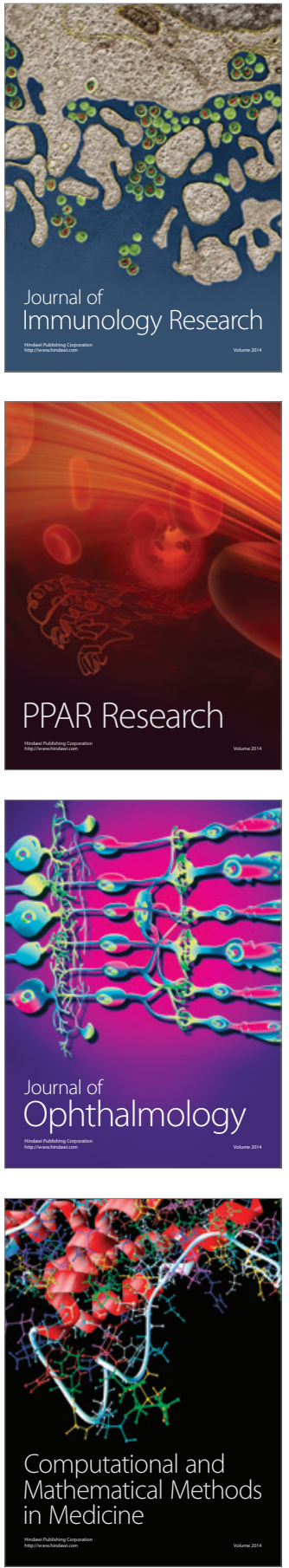

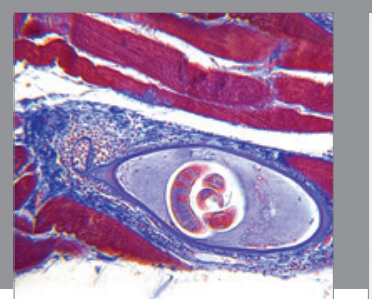

Gastroenterology Research and Practice

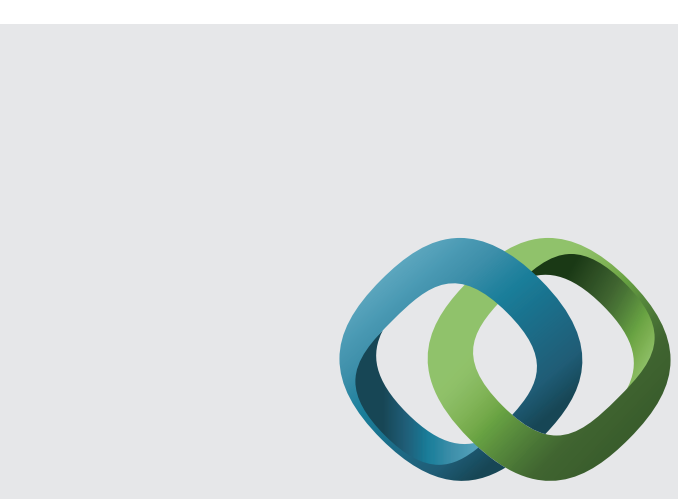

\section{Hindawi}

Submit your manuscripts at

http://www.hindawi.com
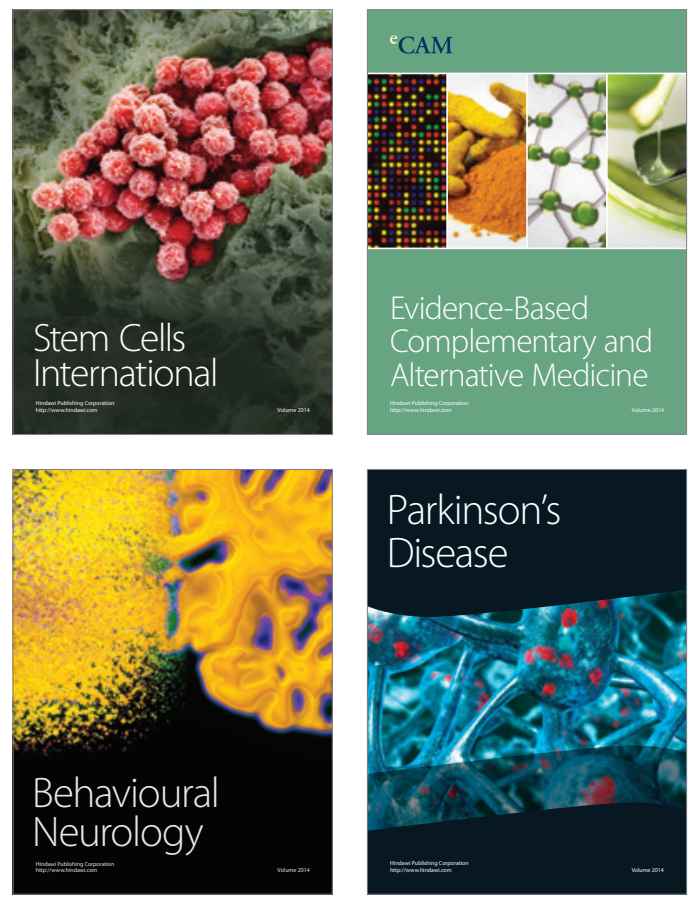
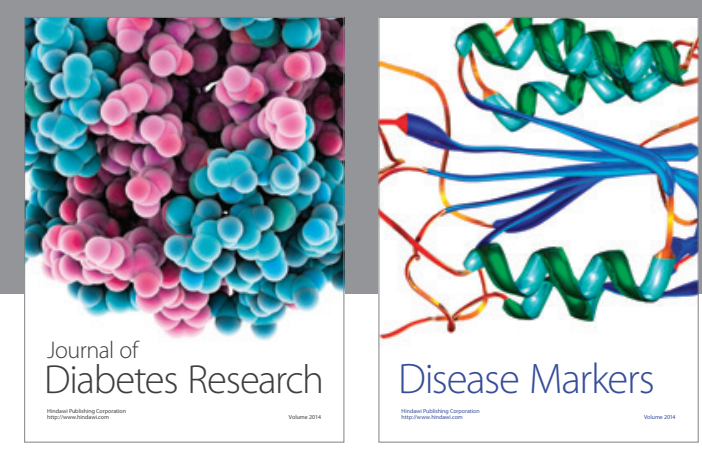

Disease Markers
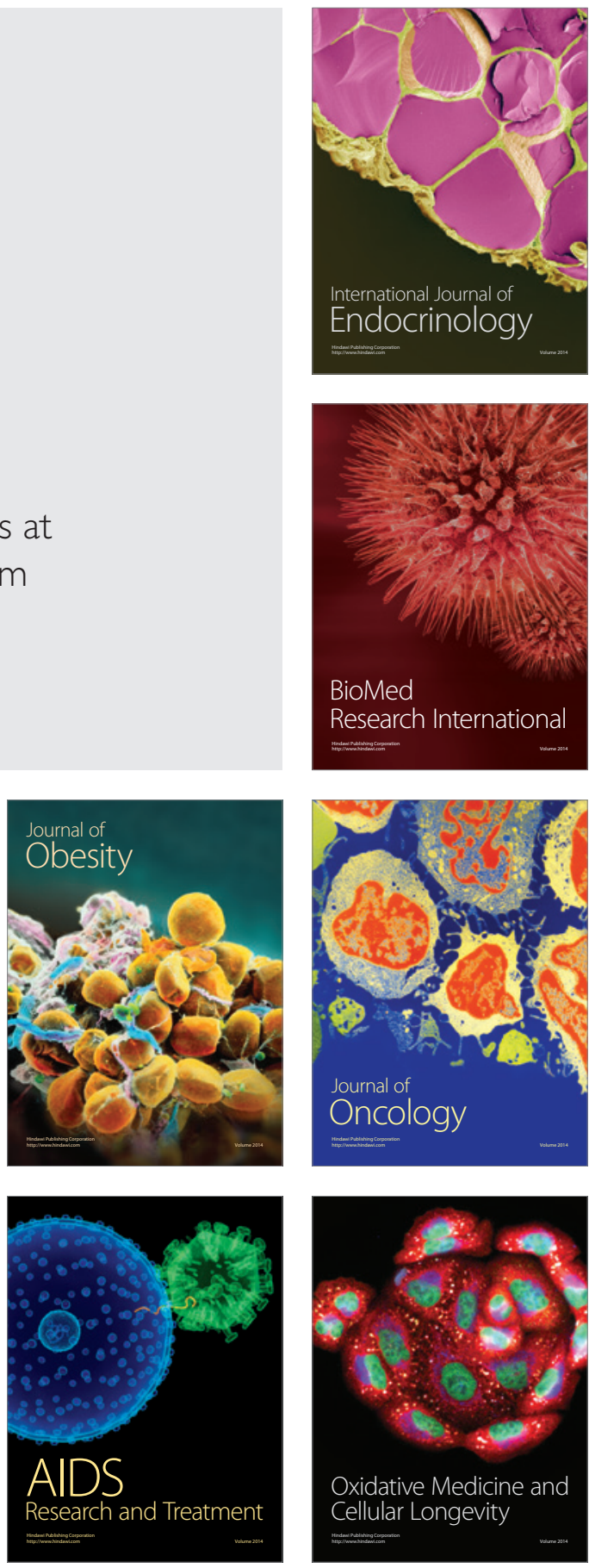